\title{
Cellular hypersensitivity to uveal pigment confirmed by leucocyte migration tests in sympathetic ophthalmitis and the Vogt-Koyanagi-Harada syndrome
}

\author{
HELGA HAMMER \\ From the Department of Ophthalmology, University Medical School, Szeged, Hungary
}

For the laboratory confirmation of cellular hypersensitivity responses the inhibition of cell migration is widely used. This procedure is based upon the observations of Rich and Lewis (1932), who found a reduced radial migration of macrophages from spleen explants of tuberculin-sensitive guinea-pigs in the presence of tuberculin, in contrast to those originating from Mantoux-negative animals. The inhibition of macrophage migration is nowadays most frequently examined in the manner described by George and Vaughan (1962): from a capillary tube containing the peritoneal exudate of guinea-pigs its cells migrate out in the same way as do the motile cells of the spleen explant, and this cell migration also may be inhibited by specific antigens. According to the investigations of David, Al-Askari, Lawrence, and Thomas (1964) the cell migration is inhibited by antigens causing delayed hypersensitivity only, and this phenomenon is unrelated to humoral immunity. The inhibition is due to a soluble protein (migration inhibitory factor, MIF) synthesized by the immunocompetent lymphocytes found between the peritoneal cells when the former come in contact with the specific antigen, MIF decreasing the motility of macrophages (David, I966; Bloom and Bennett, r966).

The studies of Søborg and Bendixen (1967) and Søborg ( 1967 ) demonstrated the migration of the leucocytes separated from the peripheral blood leaving the capillary tube container in the same way as the peritoneal macrophages; the migration of leucocytes can also be inhibited by antigens causing delayed hypersensitivity. The inhibition of leucocyte migration has since become widely used to investigate antimicrobial, antitumour, and antitransplant immunity of the delayed type, and also autoimmune diseases and drug allergy (Révillard, I97I; Dobozy, Hunyadi, and Simon, I973).

The present paper gives an account of our investigations in performing leucocyte migration tests with uveal pigment as antigen from the blood of patients suffering from sympathetic ophthalmitis and the Vogt-Koyanagi-Harada syndrome, respectively. In both diseases, earlier anti-uveal antibodies and lymphocytes hypersensitive to uveal antigen were demonstrated in the peripheral blood (Kahán, Sztanojevits, Szabados, Vass, and Szabó, I964; Mills and Shedden, I965; Hammer, 1971; Wong, Anderson, and O’Brien, I97 I).

Marak, Font, Johnson, and Alepa (197I) and Marak, Aye, and Alepa (1973) prepared separately uveal and pigment epithelial antigens and found blastogenic activity of the latter only in sympathetic ophthalmitis. 


\section{Methods}

The examinations were carried out on two patients suffering from the Vogt-Koyanagi-Harada syndrome, four with sympathetic ophthalmitis, and eight ophthalmologically healthy subjects. With the exception of the last patient with sympathetic ophthalmitis, they were the same as those on whom lymphocyte transformation tests had previously been carried out with uveal pigment (Hammer, I97 I).

Uveal pigment, prepared from the bovine eye and not containing soluble proteins, was used as antigen (Woods, 1925).

The leucocyte migration test was performed in the manner described by Dobozy, Schneider, Hunyadi, and Simon (1973). Plasma containing the erythrocytes or leucocytes was separated by sedimentation from blood samples collected with sodium citrate to inhibit coagulation. The leucocyte-rich plasma was centrifuged and the cells were washed with Parker I 99 medium. The washed leucocyte suspension was drawn into a capillary tube $100 \mathrm{~mm}$. in length and $1 \cdot 2 \mathrm{~mm}$. in diameter, and one end of the tube was then flame-sealed. It was next centrifuged for 10 min. at $800 \mathrm{G}$, and the tube was then cut at the boundary of the cell and liquid layers. The part containing the cells was fixed onto the bottom of a tissue-culture vessel with solid paraffin, and covered with Parker I99 medium containing $100 \mu \mathrm{g} . / \mathrm{ml}$. streptomycin and penicillin. At least four cultures were prepared from each patient examined: the uveal pigment was added to two of these, and the other two served as controls. After cultivation for $24 \mathrm{hrs}$ at $37^{\circ} \mathrm{C}$., the migrated area was projected, circumscribed, and measured planimetrically. The extent of inhibition is expressed by the migration index, which is the ratio of migrations of the culture containing the antigen and the control culture, respectively.

\section{Results}

The first step in the experiments was the determination of the optimal concentration of the uveal pigment which gave rise to the most extensive inhibition of migration (Table I).

Table I Determination of optimal migration-inhibitory concentration of uveal pigment

\begin{tabular}{|c|c|c|}
\hline \multirow{2}{*}{$\begin{array}{l}\text { Concentration of } \\
\text { uveal pigment } \\
(\mu \mathrm{g} . / \mathrm{ml} .)\end{array}$} & \multicolumn{2}{|l|}{ Migration index } \\
\hline & $V-K-H$ syndrome & Sympathetic ophthalmitis \\
\hline 2 & 0.83 & $0 \cdot 76$ \\
\hline 5 & 0.56 & $0 \cdot 54$ \\
\hline 20 & $0 \cdot 58$ & $0.6 \mathrm{I}$ \\
\hline 100 & $0 \cdot 70$ & 0.58 \\
\hline
\end{tabular}

Ten cultures each were prepared from one patient with sympathetic ophthalmitis and one with the Vogt-Koyanagi-Harada syndrome; $2 \mu \mathrm{g} . / \mathrm{ml}$. uveal pigment was added to each of two cultures, $5 \mu \mathrm{g} . / \mathrm{ml}$. to each of a second pair, $20 \mu \mathrm{g} . / \mathrm{ml}$. to each of a third pair, and I0o $\mu \mathrm{g} . / \mathrm{ml}$. to each of a fourth pair. The two remaining pairs of cultures served as controls. In both patients the greatest inhibition of migration was obtained with $5 \mu \mathrm{g} . / \mathrm{ml}$. uveal pigment, and further increase of the amount of antigen no longer decreased the leucocyte migration. For this reason, all further experiments were carried out with $5 \mu \mathrm{g} . / \mathrm{ml}$. uveal pigment.

The experimental results are summarized in Table II. In all patients with sympathetic ophthalmitis or the Vogt-Koyanagi-Harada syndrome, the $5 \mu \mathrm{g} . / \mathrm{ml}$. uveal pigment reduced the leucocyte migration, and in every case the migration index was less than $0 \cdot 8$.

The leucocyte migration was not decreased in the ophthalmologically healthy subject; the migration index was between $0 \cdot 87$ and $\mathrm{x} \cdot 08$ in all of them. 
Table II Effect of $5 \mu \mathrm{g} . / \mathrm{ml}$. uveal pigment on leucocyte migration in patients with Vogt-Koyanagi-Harada syndrome and sympathetic ophthalmitis, and in healthy subjects

\begin{tabular}{|c|c|c|}
\hline Patient No. & Diagnosis & Migration index \\
\hline I & V-K-H syndrome & $0 \cdot 56$ \\
\hline 2 & , & $0 \cdot 43$ \\
\hline 3 & Sympathetic ophthalmitis & 0.54 \\
\hline 4 &, & $0 \cdot 80$ \\
\hline 5 & , & 0.62 \\
\hline 6 & , & $0 \cdot 74$ \\
\hline 7 & Healthy & $\mathrm{I} \cdot 04$ \\
\hline 8 & , & 0.92 \\
\hline 9 & , & 0.87 \\
\hline io & , & $\mathrm{I} \cdot 02$ \\
\hline I I & , & $\mathrm{I} \cdot 08$ \\
\hline 12 & , & 0.96 \\
\hline 13 &, & 0.91 \\
\hline 14 & , & $0 \cdot 95$ \\
\hline
\end{tabular}

\section{Discussion}

Sympathetic ophthalmitis is a granulomatous uveitis developing in both eyes after a penetrating injury to one eye; it is in all probability an autoimmune process induced by immunocompetent lymphocytes coming into contact with the uveal pigment of the injured eye. The antigenic role of the uveal pigment in the pathogenesis of the disease was first suspected by Elschnig (I9I0), and it was later prepared free from soluble proteins by Woods (I92 I) from bovine uvea.

Friedenwald (1934) injected this pigment intracutaneously into patients with sympathetic ophthalmitis; 2 to 3 week laters the injected area was excised, and epithelioid cells surrounded by a lymphocytic reaction pathognomonic of sympathetic ophthalmitis were found. Collins (1949) injected uveal pigment suspended in Freund's adjuvant into the paw of guinea-pigs and induced thereby a very intense lymphocytic, granulocyte-free infiltration of the uvea, which corresponded in every respect to the pathology of sympathetic ophthalmitis. In recent years a number of authors have been able to demonstrate antibodies to the uveal pigment in the serum of patients with sympathetic ophthalmitis (Kahán and others, I964; Mills and Shedden, 1965), and lymphocytes sensitized against uveal pigment in the peripheral blood (Hammer, I97I ; Wong and others, I97I; Marak and others, 1973). Apart from the eye, the Vogt-Koyanagi-Harada syndrome is accompanied by a lymphocytic granulocyte-free infiltration of the various tissues containing melanin with consequent widespread damage, and it is possible to detect antibodies circulating in the serum of these patients, and, by means of the lymphocyte transformation test, lymphocytes sensitized against melanin in the peripheral blood (Kahán and others, 1964; Hammer, 1971). Circulating anti-melanin antibodies have also been successfully demonstrated in vitiligo, one of the signs found in the Vogt-Koyanagi-Harada syndrome (Langhof, Feuerstein, and Schabinski, I965). 
A number of methods are employed in vitro in various autoimmune diseases to confirm the existence of delayed-type hypersensitivity. At times, however, the various tests give different results in the same patient; for example, the investigations of Nerup, Anderson, and Bendixen ( 1969 ) showed an inhibited migration of leucocytes originating from patients with idiopathic Addison's disease, by a foetal adrenal extract, while this antigen did not induce the blastic transformation of lymphocytes in the same patients.

In certain autoimmune diseases the study of pathogenesis is made difficult by the occurrence of an inhibitory factor interfering with lymphocyte reactivity (Gery-Brand-Auraban, Benezra, Jacob, and Davies, I968). Consequently it is advisable to use various methods to confirm the autoimmune nature of different diseases in vitro.

In both sympathetic ophthalmitis and the Vogt-Koyanagi-Harada syndrome, antimelanin autoantibodies and melanin-sensitized lymphocytes have been demonstrated in the peripheral blood. The finding that leucocyte migration is specifically inhibited by uveal pigment in these diseases further supports the idea of their cellular autoimmune nature.

\section{Summary}

A study was made with the leucocyte migration test of the cellular hypersensitivity to uveal pigment of patients suffering from sympathetic ophthalmitis and the Vogt-KoyanagiHarada syndrome. It was found that $5 \mu \mathrm{g} . / \mathrm{ml}$. uveal pigment decreased the leucocyte migration of these patients while that of ophthalmologically healthy subjects remained undisturbed.

\section{References}

BLOOM, B. R., and BENNETT, B. (1966) Science, 153, 80

Collins, R. C. (1949) Amer. J. Ophthal., 32, 1687

DAVID, J. R. (1966) Proc. nat. Acad. Sci. (Wash.), 56, 72

- AL-ASKARI, S., LAWrence, H. S., and thomas, L. (1964) $\quad$ J. Immunol., 93, 264

DOBOZy, A., HUNYADI, J., and simon, N. (1973) Berufs-Dermatosen, 21, 137

- SCHNeIDER, I., HUNYADI, J., and simon, N., (1973) Acta derm.-venereol. (Stockh.), 53, 35

elschnig, A. (1910) v. Graefes Arch. Ophthal., 76, 509

FRIEDENWALD, J. s. (1934) Amer. F. Ophthal., 17, 1008

george, M., and vaughan, J. H. (1962) Proc. Soc. exp. Biol. (N.Y.Y.), III, 5 I4

Gery, I., BRAND-AURABan, A., Benezra, D., JACoB, A., and Davies, A. M. (1968) Clin. exp. Immunol.,

3, 717

HAMMER, H. (1971) Brit. F. Ophthal., 55, 850

kahán, A., sztanojevits, A., sZabados, т., vass, z., and szabó, м. (1964) v. Graefes Arch. Ophthal., 167,246

¿ANGHOF, H., FEUERSTEIN, M., and SChABINSKI, G. (1965) Hautarzt, 16, 209

MARAK, G. E., AYE, M. S., and ALEPA, F. P. (1973) Invest. Ophthal., 12, 380

- FONT, R. L., JOHNSON, M. C., and ALEPA, F. P. (1972) Ibid., 10, 770

MILls, P. v., and SHEDDEN, w. I. (1965) Brit. F. Ophthal., 49, 29

NERUP, J., ANDERSON, v., and BENDIXEN, G. (1969) Clin. exp. Immunol., 4, 355

RÉVIllaRD, J. P. (ed.) (1971) “Cell-Mediated Immunity". Karger, Basel

RICH, A. R., and LEWIs, M. R. (1932) Bull. Fohns Hopk. Hosp., 50, I I 5

søвов,, м. (1967) Acta med. scand., 182, 167

and BENDIXEN, G. (1967) Ibid., 181, 247

WONG, v. G., ANDERSon, R., and o'brien, P. J. (1971) Amer. F. Ophthal., 72, 960

woods, A. c. (1921) J. Amer. med. Ass., 77, 1317

(1925) Trans. ophthal. Soc. U.K., 45, 208 